\title{
Keratinocytic epidermal nevus syndrome with Schwann cell proliferation, lipomatous tumour and mosaic KRAS mutation
}

Said Farschtschi ${ }^{1 \dagger}$, Victor-Felix Mautner ${ }^{1 * \dagger}$, Silke Hollants ${ }^{2}$, Christian Hagel ${ }^{3}$, Marijke Spaepen ${ }^{4}$, Christoph Schulte ${ }^{5}$, Eric Legius ${ }^{2,4}$ and Hilde Brems ${ }^{2}$

\begin{abstract}
Background: Keratinocytic epidermal nevus syndrome (KENS) is a complex disorder not only characterized by the presence of epidermal nevi but also by abnormalities in the internal organ systems. A small number of cases with KENS are molecularly characterized and reported in the literature with somatic activating RAS, FGFR3 and PIK3CA mutations.

Case presentation: In this study we present a patient with hyper- and hypopigmented regions, verrucous pigmented skin lesions and a paravertebral conglomerate tumour at the level of the cervical and thoracic spine. A large lipomatous dumbbell tumour caused atrophy of the spinal cord with progressive paraparesis. We identified a mosaic c.35G > A (p.Gly12Asp) KRAS mutation in the pigmented verrucous epidermal nevus tissue, the intraneural schwann cells and the lipoma. The c.35G > A (p.Gly12Asp) KRAS mutation was absent in the peripheral blood leukocytes.
\end{abstract}

Conclusion: We conclude that KENS, the intraneural Schwann cell proliferation and the lipoma in this individual were caused by a postzygotic and mosaic activating c.35G > A (p.Gly12Asp) KRAS mutation.

Keywords: Keratinocytic epidermal nevus syndrome, KRAS, Mosaicism, RASopathy, Somatic mutation

\section{Background}

Ras proteins play a crucial role in cellular growth factor signaling. RAS mutations, found in $30 \%$ of human tumours, have an activating effect on the protein, are oncogenic and activate a number of downstream pathways [1].

Non-organoid keratinocytic epidermal nevus (KEN) is characterized by benign congenital hyperpigmented skin lesions following Blaschko's lines. Epidermal nevi with localized epidermal thickening are present at birth or become visible during early childhood. KEN in association with extracutaneous lesions in brain, muscular skeleton or eye is defined as keratinocytic epidermal nevus syndrome (KENS). Neurological abnormalities can include seizures, cognitive impairment, developmental delay and

\footnotetext{
* Correspondence: v.mautner@uke.uni-hamburg.de

${ }^{\dagger}$ Equal contributors

'Department of Neurology, University Medical Center Hamburg-Eppendorf, Martinistrasse 52, 20246 Hamburg, Germany
}

Full list of author information is available at the end of the article hemiparesis. Potential skeletal abnormalities are abnormal curvature of the spine and incomplete bone formation.

Mosaic FGFR3, PIK3CA and RAS mutations are recognized in KEN with $H R A S$ as the most prevalent mutated gene [2-4]. RAS mutations are reported in mosaic RASopathies i.e. non-organoid KEN, sebaceous nevus and in extra-cutaneous manifestations of the corresponding syndromes, KENS and Schimmelpenning syndrome $[5,6]$.

Only a few patients with epidermal nevus syndrome are molecularly characterized. In the context of understanding the phenotype-genotype in RASopathies, especially in epidermal nevus, we describe a patient with hyperpigmentation and severe neuroskeletal abnormalities.

\section{Case presentation}

The patient was born by Caesarean section (weight $3760 \mathrm{~g}$, length $55 \mathrm{~cm}$ ) and developed normal speech, while motor development was delayed (free sitting at 12 months, back to belly turn at 13 months, pulling into 


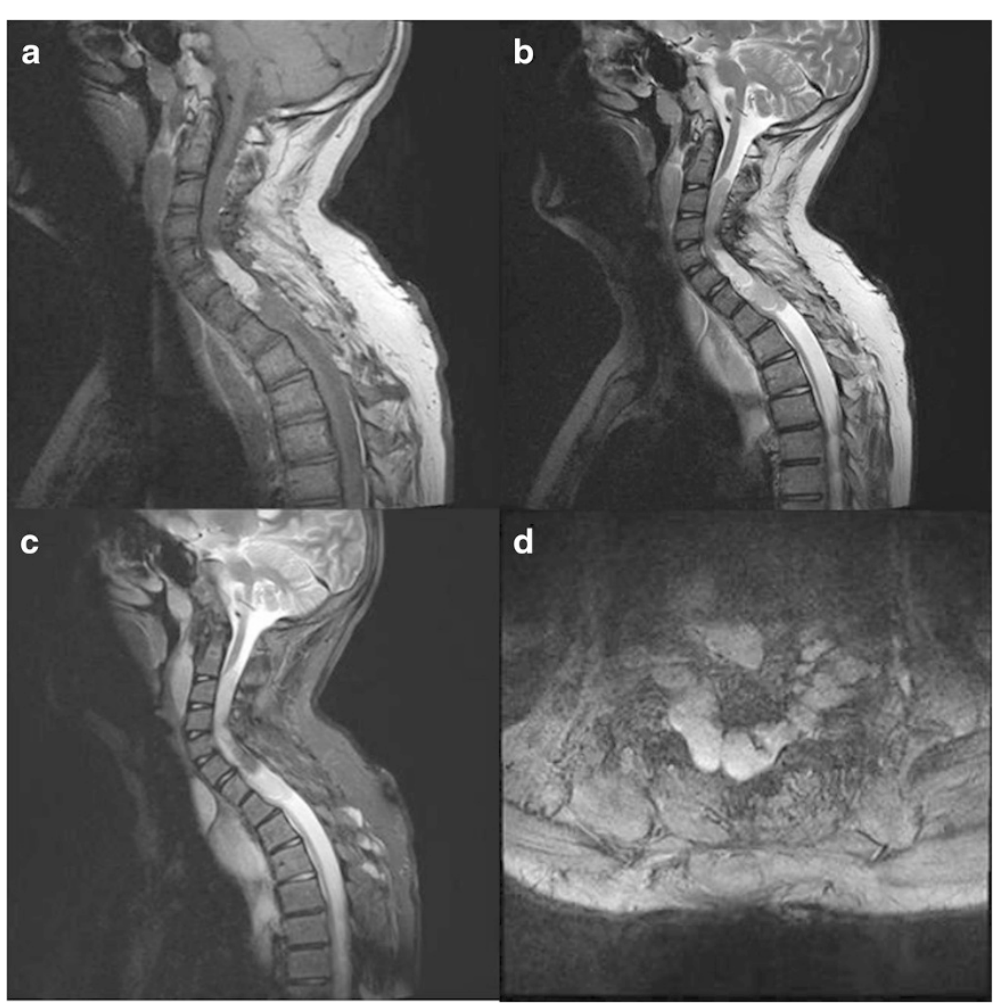

Figure 1 3T-MRI of the upper spine: T1 weighted sagittal image showing a large cervical and thoracic tumour mass (a). T2 weighted sequences (b) detect extensive intraspinal tumour formations, partially fat-isointense on fat-suppressed sequences (c). Transversal T2-images show the dimensions of the paravertebral mass $(\mathbf{d})$.

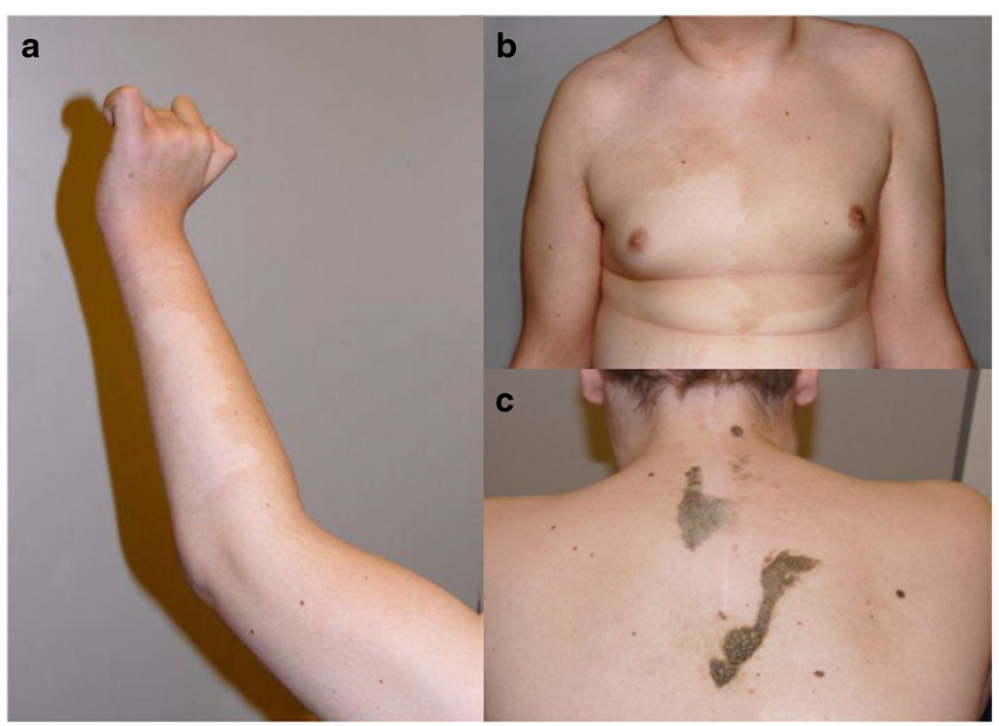

Figure 2 Clinical findings of the skin by follow-up presentation: Large inhomogeneous hyper-and hypopigmentation of the upper extremities (a) and the trunk (b) with serrated and polycyclic borders. Verruceal corneated mass on the upper back with tongue shaped tails and granular surface; median scar from precious neurosurgical intervention (c). 
stand at 18 months). Within the first years of life, the patient developed pain in the left arm as well as progressive paraparesis. Surgical removal of compressive intraspinal, extramedullar components of a tumour was performed at the age of 4 years with tumour reduction and partial relief of symptoms.

At 14 and 16 years of age follow up MRI demonstrated a large paravertebral conglomerate tumour next to the cervical and thoracic spine with extensive additional intraspinal components (Figure 1a-d). Consecutively, there was severe narrowing of the spinal canal with spinal cord compression. The intraspinal tumour was a long cylindrical, inhomogeneously configured mass, which filled the spinal canal incompletely from C3 to T1. In addition, there was a remarkably large intraspinal lipoma located between $\mathrm{C} 5$ to $\mathrm{C}$, which showed typical bright pillow-like tissue (fat isointense on T1 weighted imaging) presenting dark in T2-weighted fat suppressed sequences. The spinal nerves (C3-T1) on both sides showed cylindrical or dumbbell-like thickening with intraspinal expansion, so that the spinal cord was compressed from the right side below C3. Consecutively, there was atrophy of the spinal cord below segment T2. Additionally a right convex thoracolumbar scoliosis was found. Cranial MRI showed no abnormalities. Ophthalmologic examination showed bilateral impaired vision (50\%) and astigmatism with no Lisch nodules or other abnormalities.

At follow-up at 17 years of age he showed a large hyperpigmentation and hypopigmentation of upper body parts ranging from the trunk to the arms. There was partly polycyclic/polygonal hyperpigmentation of chest and back (Figure 2a,b), more pronounced on the left. An interscapular large segmented dark hyperpigmentation area with a verruccal epidermal nevus of about $20 \times 10 \mathrm{~cm}$ and $15 \times$ $3 \mathrm{~cm}$ was present (Figure 2c). The hyperkeratotic surface was partially fissured and the patches sharply bordered.

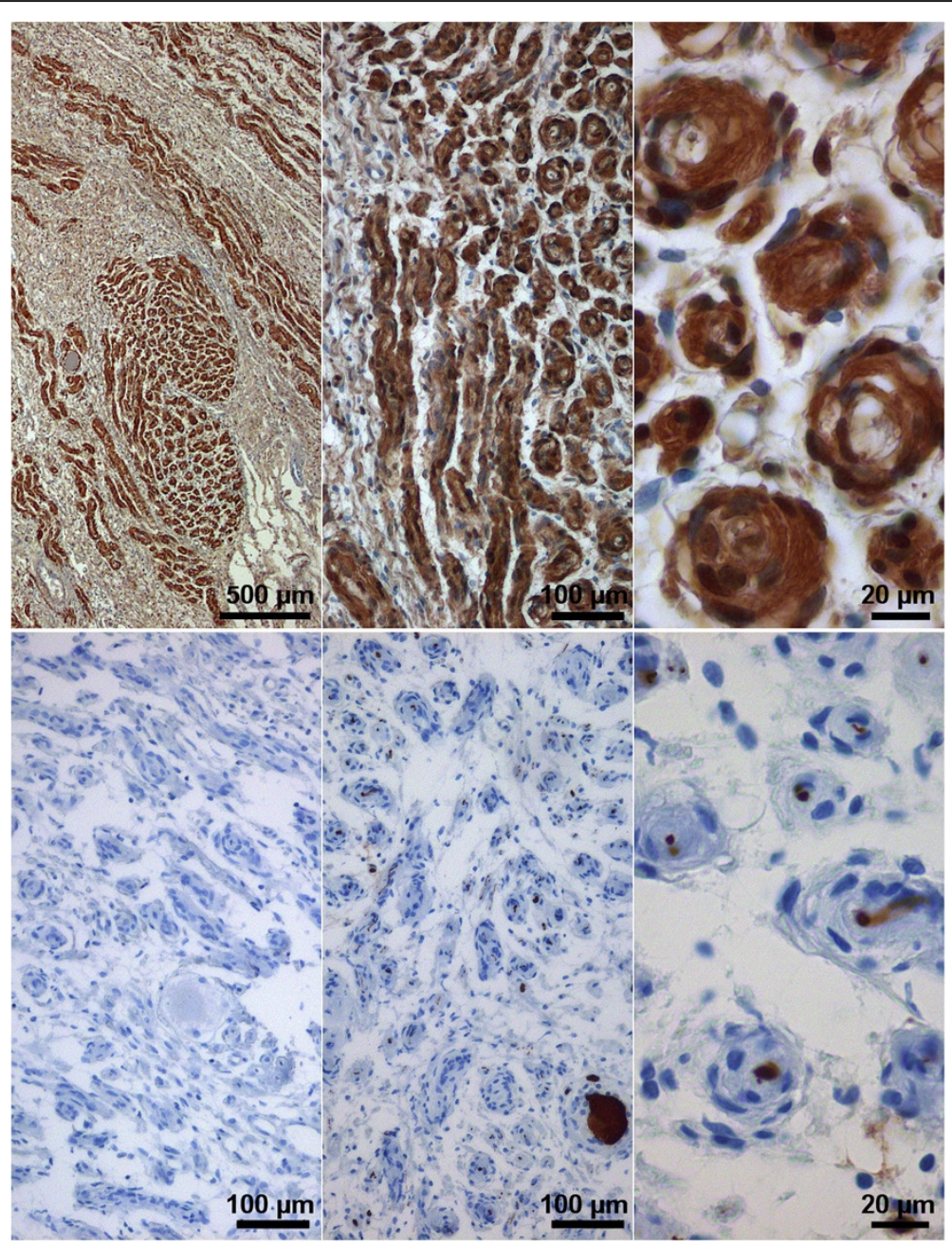

Figure 3 Hypertrophic changes in a nerve root located within a conglomerate tumor. Upper row, nerve root with hypertrophic nerve fascicles with extensive onion bulb formation by S-100-protein expressing schwann cells; lower row, left, lack of EMA expression in the tissue; middle and right, neurofilament detection in a neuron and axons in the center of onion bulbs. 
Repeated admissions to clinical geneticists raised suspicion upon a genetic disorder and the tentative diagnosis of Neurofibromatosis type 1 was made.

Neurological examination showed mild talipes equinovarus and slow progressive incomplete paraparesis of the legs with increased muscle tonus and spasticity. There was a positive Babinski reflex (pyramidal sign) and a missing cremaster- and sphincter ani reflex. Cranial nerve dysfunction was not seen. Since there was chronic slow progressive weakness of finger extension of digits III-V of the left hand, grabbing is only possible with digit I and II. To date there is still progressive transversal spinal cord syndrome with spasticity, paraparesis and pain. The patient is wheel chair bound and only can stand upright with assistance. The patient has a proximal neuropathy and no evidence for a distal neuropathy, since electromyography analysis is normal. Recent whole body MRI and DXA showed osteopenia, although normal FGF23 and low vitamin D levels were present in the blood sample of this individual.

At age 4 after tumor removal histology was performed of skin (verruca), intraneural tissue and lipoma tissue.

\section{Materials and methods}

\section{Immunohistochemistry}

For routine diagnostics an H\&E staining was performed on $4 \mu \mathrm{m}$ thick sections from formalin-fixed, paraffinembedded (FFPE) tissue. For immunohistochemical labelling sections from FFPE tissue were pretreated and incubated with primary antibodies against S-100-protein (DAKO, Hamburg, Germany, \# Z 0311, 1:8000), epithelial membrane antigen (EMA, DAKO, \# M 0613, 1:200) and neurofilament (DAKO, \# M0762, 1:800) in an automated stainer (Ventana Medical Systems, Tucson, AZ, USA) according to standard protocols. As detection was the peroxidase method used with diaminobenzidine as chromogen (Ultraview DAB, 760-500, Ventana).

\section{Mutation analysis}

The DNA was extracted from blood and three FFPE tissue samples (verrucous skin, intraneural perineurioma and lipoma) by use of standard techniques. All DNA samples were screened for the following RAS and PIK3CA mutations: c.37G > C (p.Gly13Arg) in HRAS (NM_005343.2) and c.35G > A (p.Gly12Asp) in KRAS (NM_004985.3) and c.1258 T > C (p.Cys420Arg), c.1624G > A (p.Glu542Lys) and c.3140A > G (p.His1047Arg) in PIK3CA (NM_006218.2). In total, 5 primer pairs were designed to maximum amplify the corresponding fragments of $300 \mathrm{bp}$ (primer sequences available on request). All primers were tagged with M13 sequences to facilitate sequencing. The PCR products were bidirectionally Sanger sequenced and run on an ABI sequencer.

All procedures performed were in accordance with the Declaration of Helsinki.

\section{Results}

Histological sections of the three samples showed a typical lipoma and skin with hyperplasia confirming verrucous epidermal hyperplasia. In the nerve tissue ganglion cells and spindle shaped cells arranged in concentric patterns were observed resembling a perineurioma or onion bulb formation, morphologically not consistent with a schwannoma or neurofibroma. There was no nuclear atypia and no mitoses.

Upon immunohistochemical labelling with antibodies against S100 protein, neurofilament and EMA, the onion bulb structures were strongly positive for S-100protein (Figure 3 upper row) and commonly contained a neurofilament-positive central axon (Figure 3 lower row). No EMA expression was detected (Figure 3).

Previously, neurofibromatosis type 1 was clinically and genetically ruled out. None of the specific mutations in the HRAS or PIK3CA genes were found in the DNA extracted from the three tissue samples. However, in all three samples the c.35G > A (p.Gly12Asp) missense mutation in the KRAS gene was detected. The c.35G > A (p.Gly12Asp) mutation in KRAS was in all three samples present in a heterozygous state (Figure 4), with an average allele frequency of $44 \%$ in the hyperpigmented verrucous skin sample, $49 \%$ in the tumor sample with the concentric intraneural Schwann cell proliferation and 56\% in the lipoma sample

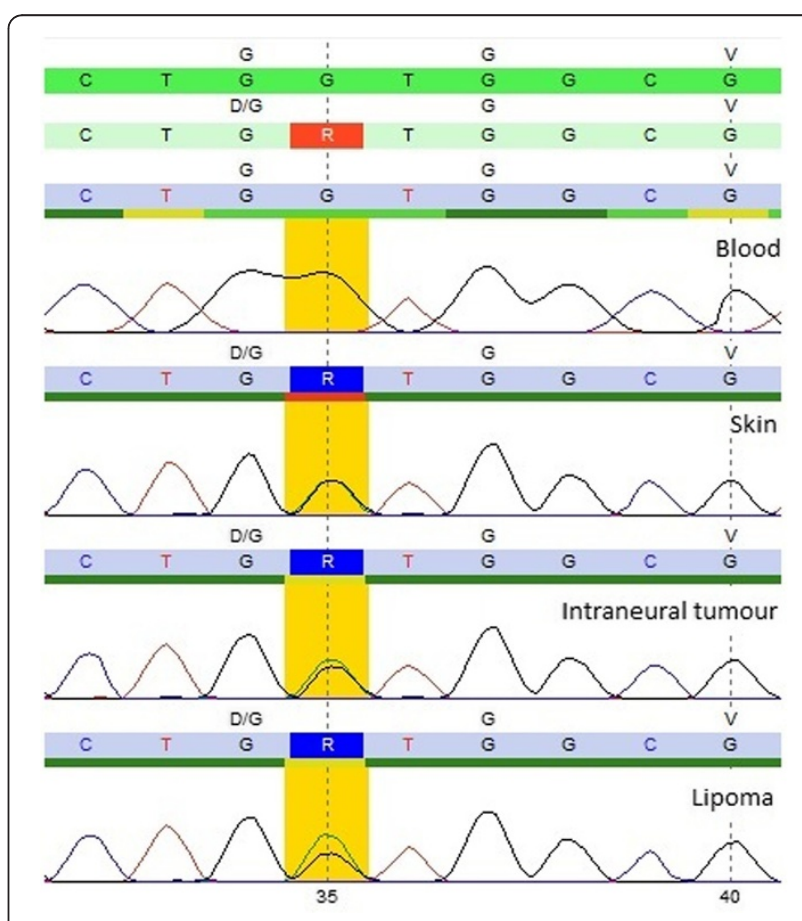

Figure 4 Sanger sequences showing the c.35G > A (p.Gly12Asp) mutation (in yellow) in the KRAS gene in the skin sample, in the tumor sample with concentric intraneural Schwann cell proliferation and in the lipoma sample. This mutation was not present in the blood sample from the patient. 


\section{Table 1 Clinical characteristics of patients with KENS in the literature}

\begin{tabular}{|c|c|c|c|c|c|c|c|c|}
\hline Case ${ }^{\text {(reference) }}$ & 1 [9] & $2[10]$ & $3[11]$ & $4[12]$ & $5[13]$ & $6[14]$ & 7 [15] & $8[8]$ \\
\hline $\begin{array}{l}\text { Age at presentation } \\
\text { (years) }\end{array}$ & Newborn & 19 & 14 & 17 & 12 & 5 & Newborn & 21 \\
\hline Sex & $\mathrm{F}$ & M & M & $\mathrm{F}$ & $\mathrm{F}$ & $\mathrm{F}$ & $\mathrm{F}$ & M \\
\hline Clinical features & $\begin{array}{l}\text { EN following lines } \\
\text { of Blaschko, } \\
\text { rhabdomyosarcoma, } \\
\text { micropolycystic } \\
\text { kidneys and growth } \\
\text { retardation }\end{array}$ & $\begin{array}{l}\text { EN, urothelial-cell } \\
\text { carcinoma of the } \\
\text { bladder }\end{array}$ & $\begin{array}{l}\text { Multiple EN, } \\
\text { hypotonia of the right } \\
\text { arm, thymoma, cystic } \\
\text { lesions in hand and } \\
\text { cervical bones }\end{array}$ & $\begin{array}{l}\text { Systemic EN } \\
\text { following the lines } \\
\text { of Blaschko sharply } \\
\text { bounded by } \\
\text { ventral midline, } \\
\text { scoliosis }\end{array}$ & $\begin{array}{l}\text { Extensive EN } \\
\text { and mild facial } \\
\text { dysmorphy }\end{array}$ & $\begin{array}{l}\text { Systematized EN, } \\
\text { seizures, delayed } \\
\text { language and } \\
\text { psychomotor } \\
\text { development, } \\
\text { brain abnormalities }\end{array}$ & $\begin{array}{l}\text { Verrucous } \\
\text { hyperpigmented } \\
\text { streaks sharply } \\
\text { demarcated at } \\
\text { midline, seizures and } \\
\text { brain abnormalities } \\
\text { ( } 6 \text { months) }\end{array}$ & $\begin{array}{l}\text { Multiple EN, } \\
\text { multiple spinal } \\
\text { tumors, lipoma, } \\
\text { duplic renal } \\
\text { arteries, ectasia of } \\
\text { aorta, scoliosis }\end{array}$ \\
\hline \multirow[t]{2}{*}{ Gene mutation } & KRAS & HRAS & HRAS & FGFR3 & FGFR3 & FGFR3 & FGFR3 & PIK3CA \\
\hline & $\begin{array}{l}\text { c.35G > A } \\
\text { (p.Gly12Asp) }\end{array}$ & $\begin{array}{l}\text { c.34G > A } \\
\text { (p.Gly12Ser) }\end{array}$ & $\begin{array}{l}\text { c.37G >C } \\
\text { (p.Gly13Arg) }\end{array}$ & $\begin{array}{l}\text { c.742C > T } \\
\text { (p.Arg248Cys) }\end{array}$ & $\begin{array}{l}c .742 C>T(p . \\
\text { Arg248Cys) }\end{array}$ & $\begin{array}{l}\text { c.742C > T } \\
\text { (p.Arg248Cys) }\end{array}$ & $\begin{array}{l}\text { c.746C }>\text { G } \\
\text { (p.Ser249Cys) }\end{array}$ & $\begin{array}{l}\text { c.3140A > T } \\
\text { (p.His1047Leu) }\end{array}$ \\
\hline \multicolumn{9}{|l|}{ Tissue investigated: } \\
\hline -carrying mutation & $\begin{array}{l}\text { Epidermal } \\
\text { component EN, } \\
\text { rhabodmyosarcoma }\end{array}$ & $\begin{array}{l}\text { Epidermal nevus, } \\
3 \text { urothelial-cell } \\
\text { carcinomas, lung } \\
\text { metastasis, normal } \\
\text { lung tissue, blood } \\
\text { leukocytes and } \\
\text { non-malignant } \\
\text { urothelium }\end{array}$ & $\begin{array}{l}\text { Both EN and } \\
\text { thymoma }\end{array}$ & $\begin{array}{l}\text { EN, oral mucosa } \\
\text { and leucocytes }\end{array}$ & Verrucous EN & $\begin{array}{l}\text { EN, blood } \\
\text { leucocytes }\end{array}$ & $\begin{array}{l}\text { EN, the unaffected } \\
\text { skin, urothelial cells }\end{array}$ & $\begin{array}{l}\text { Spinal tissue } \\
\text { (neurofibromas) }\end{array}$ \\
\hline -mutation absent & $\begin{array}{l}\text { Dermal component } \\
\text { EN, normal skin, } \\
\text { blood }\end{array}$ & $\begin{array}{l}\text { Bladder-muscle } \\
\text { layer, } 2 \text { cutaneous } \\
\text { angiomas }\end{array}$ & Lymphocytes & $\begin{array}{l}\text { Hair roots, normal } \\
\text { skin }\end{array}$ & $\begin{array}{l}\text { Blood, buccal } \\
\text { brushings, hair } \\
\text { roots }\end{array}$ & Normal skin & Blood leucocytes & $\begin{array}{l}\text { Dermis (posterior } \\
\text { thoracic region) }\end{array}$ \\
\hline
\end{tabular}

EN: epidermal nevus; F: female; m: male. 
based on peak height of both nucleotides at position 35 . No c.35G > A (p.Gly12Asp) mutation in the KRAS gene was detected in DNA extracted from peripheral white blood cells from the patient.

\section{Discussion}

The dermatological features of the reported patient are in accordance with the phenotype of previously described patients with KENS. The patient in this study presented with hyper- and hypopigmented regions and with verrucous hyperpigmented skin lesions. In addition a paravertebral conglomerate tumour was present next to the cervical and thoracic spine with a large intraspinal lipoma causing compression and atrophy of the spinal cord with progressive paraparesis. It is the first time that a myelopathy/proximal neuropathy in combination with the presence of a lipoma is reported in KENS. Further we could identify Schwann cell proliferation within the nerve resembling onion bulb formation, however, a typical schwannoma, as described by Bertola et al. 2012 in a patient with a germline KRAS (p.Lys5Glu) mutation [7], was not demonstrated. Recently epidermal nevus syndrome was described in a patient with an intra-spinal lipoma and cervical root neurofibromas [8]. In the same paper a further case had MRI changes suggestive for lumbo-sacral nerve root tumours which were asymptomatic. This patient was clinically diagnosed with CLOVES syndrome without cooccuring epidermal nevi.

We identified the same c.35G > A (p.Gly12Asp) KRAS mutation in the hyperpigmented verrucous skin tissue, intraneural perineurioma and lipoma. This mutation was not detected in the corresponding leukocytes of the same patient. The data confirm the diagnosis of KENS as a mosaic RASopathy. This mutation has not been reported as a germline mutation in individuals with Noonan or CFC syndrome and the clinical phenotype is distinctive compared to these syndromes. The c.35G > A (p.Gly12Asp) $K R A S$ mutation has extensively been reported in tumour tissue described in the open access database COSMIC (Catalogue Of Somatic Mutations In Cancer) suggesting its strong oncogenic character. COSMIC contains information on publications, samples and mutations in cancer tissues. Codon 12 is the most frequently mutated codon of KRAS in malignancies. The c.35G > A (p.Gly12Asp) KRAS mutation has been identified frequently in cancers from colon, pancreas, lung, biliary tract and ovary.

To date, only 8 cases were diagnosed with KENS, molecularly characterized and their data are summarized in Table 1 [8-15]. Three males and 5 females were diagnosed with KENS and the age of presentation varied between newborn and 21 years. The epidermal nevus can be extensive, multiple epidermal nevi can be present or the nevus can be bounded by the ventral midline. The other clinical symptoms can differ between individuals and can potentially be very severe (brain abnormalities, benign and malignant tumours). Six different somatic mutations were identified in KENS with pathogenic mutations in the KRAS (c.35G > A), HRAS (c.34G > A, c.37G > C), FGFR3 (c.742C > T, c.746C > G) and PIK3CA (c.3140A > T) genes. The epidermal nevus was molecularly investigated in $7 / 8$ cases resulting in the identification of the responsible mutation. Leucocytes are often tested, but the mutation is frequently absent. Data for other tissues are variable as well as the percentage of mosaicism.

\section{Conclusion}

KENS patients are still young when the first potential complications occur. Therefore, it is important that patients are diagnosed as early as possible to provide a better multidisciplinary follow up and therapy when needed. If patients are diagnosed with epidermal nevi and a pathogenic KRAS, PIK3CA or FGFR3 mutation, they should undergo further medical examination and potentially also further imaging (MRI) to identify the extent of disease. Mosaicism may delay diagnosis and complicate clinical management of such cases, as genetic confirmation of disease depends on appropriate tissue sampling.

\section{Consent}

Written informed consent was obtained from the patient for publication of this Case report and any accompanying images. A copy of the written consent is available for review by the Editor of this journal. The study was carried out in compliance with the Helsinki Declaration and in accordance with the ethical requirements for case reports of the ethical board Hamburg.

\section{Abbrevations}

ABl: Applied biosystems instruments; bp: Base pairs; c.37G > C (p.Gly13Arg): Nomenclature for the description of sequence variations; C3, 5, 7: Cervikal spinal segment 3, 5, 7; CFC: Cardiofaciocutaneous syndrome; CLOVES: Congenital lipomatous overgrowth, Vascular malformations, Epidermal nevi, Scoliosis/skeletal and spinal anomalies; Cm: Centimeter; COSMIC: Catalogue of somatic mutations in cancer; DNA: Deoxyribonucleic acid; DXA: Dual-energy X-ray absorptiometry; EMA: Epithelial membrane antigen; FFPE: Formalin-fixed, paraffin-embedded tissue; FGF23: Fibroblast growth factor 23; FGFR3: Fibroblast growth factor 3; g: Gramm; H\&E: Hematoxylin and eosin stain; HRAS: HRas G-protein of the Ras subfamily; KEN: Keratinocytic epidermal nevus; KENS: Keratinocytic epidermal nevus syndrome; M13: DNA sequencing primers; MRI: Magnetic resonance imaging; PIK3CA: Phosphatidylinositol-4,5-bisphosphate 3-kinase, catalytic subunit alpha; RAS: 'Rat sarcoma'; S-100: S-100 protein-family; T1: Thoracic spinal segment 1; T1/T2-weighted: T1/T2 relaxation time; Vitamin D: Cholecalciferol.

\section{Competing interests}

The authors declare that they have no competing interests.

\section{Authors' contributions}

Study conception and design - SF, EL, HB. Acquisition, analysis and interpretation of data - SF, SH, CH, MS, CS. Drafting the manuscript or revising it critically for important intellectual content - SF, VFM, SH, EL, HB. Have given final approval of the version to be published - all authors. Agree to be accountable for all aspects of the work - all authors. 


\section{Acknowledgments}

The authors thank Ilse Van Der Heyden for technical assistance. Hilde Brems is a postdoctoral researcher of the Research Foundation Flanders (FWO) at the Catholic University of Leuven (KU Leuven). This research was supported by funding from the Belgian Science Policy Office Interuniversity Attraction Poles (BELSPO-IAP) programme through the project IAP P7/43-BeMGI.

\section{Author details}

1 Department of Neurology, University Medical Center Hamburg-Eppendorf, Martinistrasse 52, 20246 Hamburg, Germany. ${ }^{2}$ Department of Human Genetics, KU Leuven - University of Leuven, Leuven, Belgium. ${ }^{3}$ Institute of Neuropathology, University Medical Center Hamburg-Eppendorf, Hamburg, Germany. ${ }^{4}$ Department of Human Genetics, University Hospital Leuven, Leuven, Belgium. ${ }^{5}$ Institute for Heamatopathology, Hamburg, Germany.

Received: 28 October 2014 Accepted: 21 January 2015

Published online: 10 February 2015

\section{References}

1. Schubbert S, Shannon K, Bollag G. Hyperactive Ras in developmental disorders and cancer. Nat Rev Cancer. 2007;7(4):295-308.

2. Hafner C, van Oers JMM, Vogt T, Landthaler M, Stoehr R, Blaszyk H, et al, Mosaicism of activating FGFR3 mutations in human skin causes epidermal nevi. J Clin Invest. 2006;116(8):2201-7.

3. Hafner C, López-Knowles E, Luis NM, Toll A, Baselga E, Fernández A, et al. Oncogenic PIK3CA mutations occur in epidermal nevi and seborrheic keratoses with a characteristic mutation pattern. Proc Natl Acad Sci U S A. 2007:104(33):13450-4.

4. Hafner C, Toll A, Gantner S, Mauerer A, Lurkin I, Acquadro F, et al. Keratinocytic epidermal nevi are associated with mosaic RAS mutations. J Med Genet. 2012:49(4):249-53.

5. Groesser L, Herschberger E, Ruetten A, Ruivenkamp C, Lopriore E, Zutt M et al. Postzygotic HRAS and KRAS mutations cause nevus sebaceous and Schimmelpenning syndrome. Nat Genet. 2012;44(7):783-7.

6. Hafner C, Groesser L. Mosaic RASopathies. Cell Cycle. 2013:12(1):43-50.

7. Bertola DR, Pereira AC, Brasil AC, Suzuki L, Leite C, Falzoni R, et al. Multiple, diffuse schwannomas in a RASopathy phenotype patient with germline KRAS mutation: a causal relationship? Clin Genet. 2012;81(6):595-7.

8. Keppler-Noreuil KM, Sapp JC, Lindhurst MJ, Parker VE, Blumhorst C, Darling T, et al. Clinical delineation and natural history of the PIK3CA-related overgrowth spectrum. Am J Med Genet Part A. 2014;164A:1713-33.

9. Bourdeaut F, Hérault A, Gentien D, Pierron G, Ballet S, Reynaud S, et al. Mosaicism for oncogenic G12D KRAS mutation associated with epidermal nevus, polycystic kidneys and rhabdomyosarcoma. J Med Genet. 2010;47(12):859-62.

10. Hafner C, Toll A, Real FX. HRAS mutation mosaicism causing urothelia cancer and epidermal nevus. N Engl J Med. 2011;365(20):1940-2.

11. Avitan-Hersh E, Tatur S, Indelman M, Gepstein V, Shreter R, Hershkovitz D, et al. Postzygotic HRAS mutation causing both keratinocytic epidermal nevus and thymoma and associated with bone dysplasia and hypophosphatemia due to elevated FGF23. J Clin Endocrinol Metab. 2014;99(1):E132-6

12. Bygum A, Fagerberg CR, Clemmensen OJ, Fiebig B, Hafner C. Systemic epidermal nevus with involvement of the oral mucosa due to FGFR3 mutation. BMC Med Genet. 2011:12:79.

13. Collin B, Taylor IB, Wilkie AOM, Moss C. Fibroblast growth factor receptor 3 (FGFR3) mutation in a verrucous epidermal naevus associated with mild facial dysmorphism. Br J Dermatol. 2007;156(6):1353-6.

14. García-Vargas A, Hafner C, Pérez-Rodríguez AG, Rodríguez-Rojas LX, González-Esqueda P, Stoehr R, et al. An epidermal nevus syndrome with cerebral involvement caused by a mosaic FGFR3 mutation. Am J Med Genet A. 2008;146(17):2275-9.

15. Ousager LB, Bygum A, Hafner C. Identification of a novel S249C FGFR3 mutation in a keratinocytic epidermal naevus syndrome. Br J Dermatol. 2012;167(1):202-4

\section{Submit your next manuscript to BioMed Central and take full advantage of:}

- Convenient online submission

- Thorough peer review

- No space constraints or color figure charges

- Immediate publication on acceptance

- Inclusion in PubMed, CAS, Scopus and Google Scholar

- Research which is freely available for redistribution 